\title{
A Quarta Colônia de imigração italiana: uma paisagem cultural na região central do Rio Grande do Sul.
}

Resumo: Na paisagem da Região da Quarta Colônia de Imigração Italiana, colonizada por imigrantes italianos, tem-se materializado sobre o espaço a cultura italiana, cuja materialização é percebida diante dos artefatos que identificam a região diferenciando-a de outros espaços e resultando na formação de uma paisagem cultural. Neste sentido, o presente artigo objetiva discutir a respeito da paisagem cultural e identificar os elementos da memória italiana nesta região. Ao passo que as raízes culturais permanecem, ainda nos dias de hoje, visíveis na paisagem regional, juntamente com o forte sentimentalismo e apego as tradições italianas.

\section{The fourth Colony of Italian immigration: a cultural landscape in the central region of Rio Grande do Sul.}

\footnotetext{
Abstract: In the landscape of the region of the Fourth Colony of Italian Immigration, which was colonized by Italians, the Italian culture has been materializing over the space. The establishment of this culture is perceived in the presence of the artifacts that identify the region, differentiating it from other spaces and resulting in the formation of a cultural landscape. In this sense, this article's main objective is to raise a discussion about the cultural landscape and identify the elements of the Italian memory in that region. While the cultural roots still remain visible in the regional landscape nowadays, along with the strong sentimental attachment and Italian traditions.
}

* Acadêmica do Programa de Pós- Graduação em Geografia da UFSM, Departamento de Geociências e área Produção do Espaço e Dinâmica Regional

Palavras-chave: Geografia; Paisagem Cultural; Região da Quarta Colônia de Imigração Italiana.

Key-words: Geography; Cultural Landscape; The Region of the Fourth Colony of Italian Immigration. 


\section{Introdução}

A paisagem é considerada, pela maioria das correntes do pensamento geográfico, um conceito-chave da ciência geográfica. No entanto, após do final do século XIX, a geografia passa a abordar com mais ênfase a paisagem cultural em seus estudos acadêmicos.

Assim, no bojo de sua conceituação, a paisagem é denominada como o resultado da interação de diversos elementos entre eles: o natural, humano, social, cultural ou econômico e das quais, passa constantemente por um processo de modificação, pelo fato sofrer interferência das atividades humanas.

Então se a paisagem é este arranjo de elementos sobre o espaço, logo é importante o estudo não apenas a paisagem natural, mas aquela materializada por uma cultura em determinado espaço.

Neste contexto, este artigo aborda a respeito da paisagem cultural formada na Quarta Colônia de Imigração Italiana. Objetivando analisar a influência da cultura na construção da paisagem regional, bem como abordar os elementos culturais desta paisagem.

Através deste estudo podem-se perceber as raízes da cultura italiana fortemente alicerçada na região, das quais denota uma paisagem repleta de simbolismo e afetividade. Em suma, a memória de um passado impregnada no presente do cotidiano regional.

Aliás, estes fortes laços culturais presentes na região são decorrentes da colonização italiana, que sem dúvida, foi fundamental para desencadear o sucesso econômico e responsável pelas tradições e costumes típicos da região, além do forte sentimentalismo e religiosidade.

Assim como, a religião, elemento da cultura italiana, consiste num aspecto fortemente visualizado e cultivado nesta região. No campo do visível, a existência de inúmeras igrejas, capitéis e grutas, e no campo do invisível, a presença marcante do padre nas dinâmicas locais e regionais, sejam elas sociais ou econômicas, as festividades religiosas e a fé.

Nesta perspectiva, o sentimentalismo e afetividade dos descendentes de imigrantes que hoje vivem no lugar e continuam preservando os ambientes antigos e, sobretudo, valorização da cultura cria, através da preservação das antigas casas, objetos, fotos, dialetos, memórias entre outros, a paisagem cultural da Quarta Colônia de Imigração Italiana.

Embora, futuramente novas dinâmicas se estruturem sobre a região, mediante ao processo de globalização ou não, com certeza os elementos culturais permaneceram ativos na paisagem, pois o sentimentalismo regional é o ponto fundamental para o desenvolvimento local e para a vida destes moradores que buscam, cada vez mais, valorizar a sua identidade.

Contudo, a preservação da paisagem cultural evidente principalmente quando se adquire 0 turismo cultural na Quarta Colônia de Imigração Italiana evidencia uma maneira de impedir que as amarras do global invadam o regional e destruam a identidade cultural da região.

Mediante a abordagem desta temática, a paisagem cultural da Região da Quarta Colônia de Imigração Italiana, buscou-se estruturar o artigo em: Primeiramente, relato dos procedimentos metodológicos, seguindo de uma revisão de literaturas sobre a Geografia, cultura, paisagem e espaço, para poder posteriormente retratar a paisagem cultural da Quarta Colônia de Imigração Italiana/RS e seus artefatos culturais e consequentemente a conclusão das idéias apontadas no artigo.

Geografia Ensino \& Pesquisa, v. 16, n.2 p. 31 - 46, maio/ago. 2012

A Quarta Colônia de imigração italiana: uma paisagem cultural na região central do Rio Grande do Sul.

\section{Abordagem metodológica: procedimentos e método.}

O eixo teórico-metodológico deste trabalho focaliza-se na análise a cerca da paisagem cultural da Região Quarta Colônia de Imigração Italiana/RS. A cultura italiana atribui sobre o espaço aspectos e artefatos que marcam esta região, desde o social, o econômico, o lazer, de um modo geral a paisagem. 
Desta forma, os procedimentos metodológicos que foram empregados no desenvolvimento da pesquisa estão estruturados nas seguintes etapas. Primeiramente, realizou um levantamento bibliográfico, a fim de compreender as concepções da geografia cultural, especialmente no bojo das discussões a respeito da paisagem cultural.

Num segundo momento, foi realizada a segunda etapa da pesquisa, a coleta de dados, em fontes secundárias, Prefeitura Municipal de Nova Palma e Centro de Pesquisas Genealógicas de Nova Palma (CPG), além de consultar algumas bibliográficas que abordam a região e a questão cultural.

Na etapa seguinte, o trabalho de campo, realizou-se a observação "in loco" no qual procurou através de entrevistas e questionários, a fim de identificar a estruturação da paisagem cultural da Quarta Colônia de Imigração Italiana.

As entrevistas serão realizadas com os moradores da região estudada e como método da pesquisa foi realizado o fenomenológico, analisando a contribuição da cultura na construção da paisagem desta região. Para finalizar a análise realizou-se a interpretação dos dados obtidos através das fontes primárias e secundárias. Na seqüência do artigo discutir-se-á sobre as bases teóricas do trabalho, para depois contextualizar os resultados e discussões sobre a temática em questão.

\section{Geografia, paisagem, espaço e cultura: discussões teóricas.}

A paisagem consiste-se num elemento fortemente utilizado em estudos assim como, várias ciências utilizam-a no decorrer de suas discussões. Entre as diferentes áreas do conhecimento que trabalham com a paisagem, a geografia é uma delas, cuja paisagem é essencial na estruturação da própria ciência, sendo a paisagem a constatação da relação homem versus natureza.

Nesta perspectiva, paisagem é uma das categorias geográficas e constitui-se num ponto de análise da geografia. Já na Geografia Tradicional a paisagem foi incorporada aos estudos por Humboldt, quando a mesma passa a constituir-se como disciplina na Ciência Geográfica Alemã no século XIX. Ainda na Alemanha, a escola de Sauer e Berkeley aplica no estudo da morfologia da paisagem.

Entretanto, na geografia do final do século XIX, a geografia abordada principalmente por Ratzel e Vidal de La Blache a paisagem adquire uma conotação cultural.

Nos Estados Unidos, no entanto, originou as idéias de construção de uma geografia cultural, proposta por Carl Sauer, cuja geografia deve estudar não somente o meio físico, mas também o cultural o invisível, porém contribuinte para as alterações espaciais, buscando compreender a apropriação do espaço vivenciado e valorizado pelo homem.

Nesta abordagem, no âmbito da Nova Geografia, a paisagem passa a ser entendida como algo resultante da integração entre os aspectos físicos da paisagem e o uso que o homem faz deste espaço, numa relação entre aspectos físicos e humanos.

Diante desta perspectiva, os geógrafos perceberam a paisagem como a expressão materializada das relações do homem com a natureza num espaço circunscrito.

Todavia, nos anos oitenta, surge a Geografia Crítica, em oposição a Nova Geografia contestando assim, a vitalidade da paisagem como objeto de estudo da Geografia, pois para os defensores desta abordagem, é o espaço ao invés da paisagem o elemento principal das discussões e a partir deste se dá o entendimento dos demais aspectos naturais, humanos e culturais.

Recentemente, entretanto, o conceito de paisagem cultural foi adotado dentro das políticas públicas brasileiras do Instituto Nacional de Patrimônio Histórico e Artístico Nacional (datado fato em 18 de agosto de 2007), a partir de dois encontros: um deles, em Bagé- RS, dos quais instituiu a Carta de Bagé ou Carta das Paisagens Culturais e o outro aconteceu em Bonito, no Mato Grosso do Sul, resultante deste último a Carta da Serra da Bodoquena - Carta das Paisagens Culturais e

Geografia Ensino \& Pesquisa, v. 16, n.2 p. 31 - 46, maio/ago. 2012 
Geoparques, considerando assim, a paisagem cultural em um espaço de preservação, porém as discussões na UNESCO quanto a este fato, decorrem a três décadas.

De acordo com MAGALHÃES (2011, p. 3):

Antes de 1992, no entanto, já se discutia internacionalmente as questões de salvaguarda das paisagens, como demonstra a Recomendação de Paris, de 12 de dezembro de 1962. Na ocasião tratou-se das paisagens e sítios, na preservação dos seus valores estéticos e culturais.

Sendo o conceito de paisagem cultural instituído pela UNESCO com a Convenção de 1972, reconhecendo dessa forma, regiões e territórios, cuja inter-relação entre a cultura humana e o ambiente natural confere à paisagem uma identidade particular e própria.

Neste sentido, a partir de 1970 muitos foram os "ganhos" científicos e políticos quanto aos estudos e conceitos referentes à paisagem e também a sua relação com o cultural. Dessa forma, a fim de tentar conceitualizar o termo paisagem, Milton Santos (1997) afirma que esta resulta da expressão materializada do espaço geográfico. Ela é o conjunto de formas que num determinado momento, exprimem as heranças que representam as sucessivas relações entre o homem e a natureza, ou ainda o autor aborda que a paisagem se dá como conjunto de objetos reais concretos.

Reforça Corrêa; Rosendahl (1998, p.9) que: "A paisagem geográfica é vista como um conjunto de formas naturais e culturais associadas em uma dada área, [...]. A paisagem cultural ou geográfica resulta da ação, ao longo do tempo, da cultura sobre a paisagem natural."

Corrêa (2001, p. 290) aponta que: "a paisagem é de um lado, o resultado de uma dada cultura que a moderou e, de outro, constitui-se em uma matriz cultural."

Ainda, Suertegaray (2001) refere-se à paisagem como: um conceito operacional, ou seja, um conceito que nos permite analisar o espaço geográfico sob uma dimensão, qual seja o da conjunção de elementos naturais e tecnificados, sócio-econômicos e culturais.

Reforça Almeida e Sartori (2008, p.111): "[...] a paisagem revela-se cheia de vida, assim como expressa sentidos contraditórios, paixões e emoções."

Nesta maneira, como a paisagem envolve as emoções os elementos culturais, Cosgrove (1998), comenta que a paisagem está associada com a Geografia Humana, com o cultural, com a idéia de formas visíveis sobre a superfície terrestre e com a sua composição. Assim, o local é um lugar simbólico, cujas culturas estão presentes.

Em síntese, a paisagem é um espaço concreto e também abstrato é uma resolução entre os valores sentimentais, culturais, o meio ambiente, e o espaço transformado pelo homem, reforçado pela relação homem e natureza.

Mas se a paisagem é uma das categorias da geografia e é definida como um espaço materializado pelas relações natureza e sociedade, o que vem a ser o espaço?

O conceito de espaço geográfico definido por Milton Santos (1997) constitui num sistema de objetos e num sistema de ações. Ainda, Santos (1997), considera o espaço como uma instância da sociedade, ao mesmo título que a instância econômica e a instância cultural ideológica.

Pode-se dizer que para geografia o espaço é constituído por paisagens. Dessa forma, a noção de espaço geográfico é mais ampla que a de paisagem, pois no espaço geográfico estão

Geografia Ensino \& Pesquisa, v. 16, n.2 p. 31 - 46, maio/ago. 2012

A Quarta Colônia de imigração italiana: uma paisagem cultural na região central do Rio Grande do Sul. presentes os elementos e aspectos que existem nas paisagens, mas também nas diversas ações que as pessoas realizam nas paisagens. Ações estas, que correspondem aos variados tipos de atividades humanas: trabalho, estudo, lazer.

De acordo com Brunet (2001), o espaço geográfico é formado pelo conjunto de populações, por suas obras, suas relações localizadas, pelo seu meio de vida. Ele nasce com o trabalho das sociedades e só tem fim com ele.

Na visão de Massey (2008) o espaço é uma simultaneidade dinâmica, constantemente alterada pela interrelacionalidade, pela permanente espera da construção de novas relações. Ainda 
nesta temática, MASSEY (2008) afirma que o espaço se faz e refaz porque as relações geram um processo de construção.

$\mathrm{Na}$ geografia, dos conceitos mais abrangentes, o espaço geográfico representa o todo do qual derivam os demais conceitos que se relacionam entre si e completam-se. Neste entendimento, o espaço é o todo, enquanto a paisagem é a forma adquirida em um determinado momento de uma porção do espaço.

Com isto, ao atribuir artefatos culturais sobre um espaço num período de tempo, observa-se as relações do homem e natureza criam paisagens culturais e estas por sua vez, estão associadas à vivência e dinâmicas das pessoas que convivem neste espaço ou habitaram-no.

Conforme Silva (2000, p.30): "Assim, a apropriação do espaço é determinada pelas relações que se estabelecem entre seus membros, pelo manejo de símbolos e códigos comuns."

Dessa maneira, a cultura é um elemento que gera as ações e valores dos que dela fazem parte, o espaço passa a absorver símbolos e códigos culturais, nas quais identificam uma determinada cultura e podem ser visíveis e reconhecidos a outros espaços do mundo, formando paisagens culturais. Estes códigos culturais podem ser definidos como: a arquitetura, a gastronomia, o modo de vida, a religião.

Diante disso, a cultura que é o modo de vida, os costumes, o modo de viver e pensar é também um elemento fundamental na construção do espaço e consequentemente da paisagem. Neste aspecto, a cultura para Claval (1999) consiste na "soma dos comportamentos, dos saberes, das técnicas, dos conhecimentos e dos valores acumulados, pelos indivíduos durantes suas vidas e, em uma outra escala pelo conjunto dos grupos de que fazem parte."

Neste sentido, a cultura italiana no território rio-grandense criou um cenário, além de inúmeras paisagens próprias às características das suas tradições, tentando reproduz nesta terra a Itália, lugar de origem deste povo.

Observa-se que dentre os símbolos mais destacado pela cultura italiana sob o espaço é a religiosidades, nas cidades colonizadas por italianos é comum a presença de santuários, capitéis, igrejas, sendo estas de extremo valor sentimental.

A produção de vinho, com a presença de inúmeros parreirais de uva também compõe a paisagem das cidades italianas e das áreas rurais. Já que é um forte habito do italiano beber vinho com a comida.

Outro elemento da materialização da cultura italiana é a presença de antigas casas construídas pelos imigrantes italianos e que muitas ainda são preservadas, estas eram construídas de pedras, com telhados inclinados, com muitas janelas. De acordo com Brum Neto (2007, p. 257):

\footnotetext{
[...] as casas guardaram as particularidade da cultura italiana trazida pelos primeiros imigrantes que apontaram no Rio Grande do Sul, seja através do estilo das construções, com telhado mais inclinado, de pedra ou madeira, separando a cozinha do restante da residência, ou pela funcionalidade [...].
}

Entre as diversas paisagens formadas pela colonização italiana no Rio Grande do Sul, estão impressos vários destes elementos culturais, que por sua vez, identificam-na. Contudo, entre estas paisagens destaca-se a paisagem cultural formada pela imigração italiana na região central do território gaúcho, dos quais resultou na Região da Quarta Colônia de Imigração Italiana.

\section{As características e os elementos culturais da paisagem da região da Quarta colônia de imigração italiana.}

A colonização da Região da Quarta Colônia de Imigração Italiana (Colônia Silveira Martins) teve inicio a partir de $1877 \mathrm{com}$ a vinda de imigrantes italianos.
Geografia Ensino \& Pesquisa, v. 16, n.2 p. 31 - 46, maio/ago. 2012 
Saquet (2003) argumenta que,

Na colônia de Silveira Martins as primeiras turmas ficaram alojadas num barracão, na base da encosta do planalto. Este lugar foi denominado de Val de Búia devido a predominância de italianos provenientes de Búia, província Údine, Itália. Em Val de Búia uns dormiam no barracão outros em barracas feitas de lençóis ou ramos esperando a distribuição dos lotes de chão. (SAQUET, 2003, p.82).

Entretanto, a chegada continua de imigrantes resultou na formação de vários núcleos interioranos associados à sede colonial deste quarto núcleo de colonização, Silveira Martins. Estes novos núcleos foram denominados: o núcleo norte, soturno, Arroio Grande, Nova Treviso, Vêneto.

Porém, no desmembramento da Colônia Silveira Martins, originou-se os atuais municípios de Silveira Martins, São João do Polêsine, Dona Francisca, Faxinal do Soturno, Ivorá, Nova Palma e Pinhal Grande, dos quais formam hoje, a Região da Quarta Colônia de Imigração Italiana.

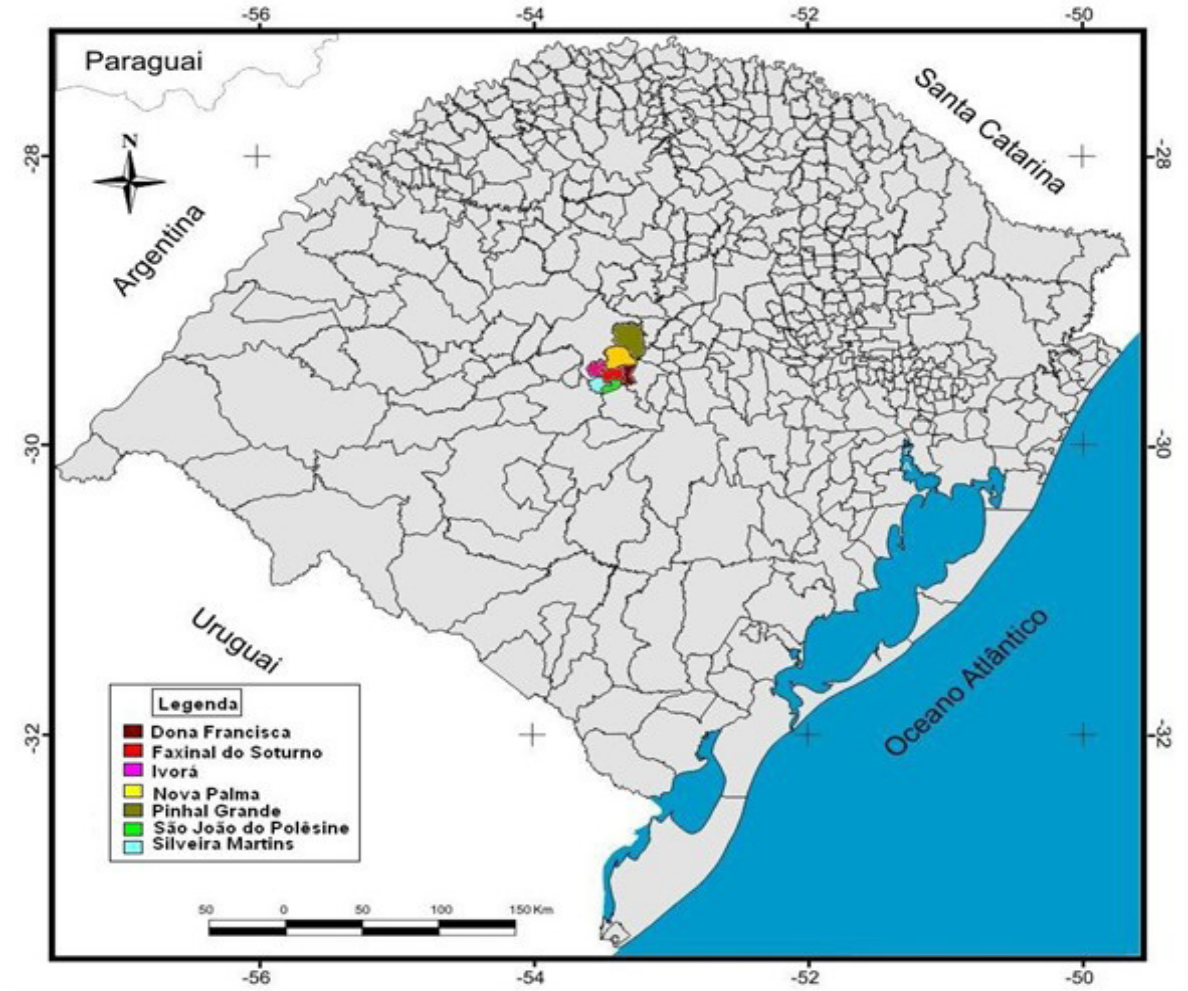

Ilustração 1 -Mapa da Região da Quarta Colônia de Imigração italiana.

Fonte: Fundação de Economia e Estatística

Org.: autor

Geografia Ensino \& Pesquisa, v. 16, n.2 p. 31 - 46, maio/ago. 2012

A Quarta Colônia de imigração italiana: uma paisagem cultural na região central do Rio Grande do Sul.
Assim, a ocupação italiana da região central do Rio Grande do Sul, através da vinda de uma população com desejos de reproduzir sua terra de origem e proporcionar o desenvolvimento local e de suas famílias acabaram transformando o espaço natural.

A valorização da história e cultura potencializou um sentimentalismo de pertença dos sujeitos locais com seus costumes e tradições advindas do processo de colonização italiana no Rio Grande do Sul, trazendo elementos de suas terras de origem, que foram alteradas a partir da vivência e das trocas culturais com outras etnias neste local. (FROEHLICH, et. al., 2009).

A preservação do espaço vivido e afetivo permanece presente entre os descendentes italianos que cultivam ainda nos dias de hoje, hábitos, dialetos, gastronomia e festividades envolvendo a cultura e a história da Quarta Colônia de Imigração Italiana. 
Destaca Torres (2009) que:

Isso se deu em virtude da colonização dos imigrantes italianos em Silveira Martins, RS, que ainda preserva fortes traços da herança italiana na arquitetura das casas, nas festividades, gastronomia, produção de vinhos, conservas, produtos de origem animal, na paisagem e territorialidades de seus habitantes mais antigos. (TORRES, 2009, p.26-27).

Conforme destacado anteriormente, a arquitetura é um dos elementos constituintes da paisagem cultural italiana, principalmente na Região da Quarta Colônia de Imigração Italiana.

Coloca (CHIAMULER, 2010, p 42) "A paisagem de Silveira Martins também é um elemento diferenciador do grupo, seja na paisagem concreta ou simbólica, seja na arquitetura ou na natureza, características que proporcionam ao grupo identificação e distinção."

Argumenta Vendruscolo $(2009$, p. 196) que: "A arquitetura preservada representa a cultura e a história materializada em monumentos e construções que tomam sentido e mantém vivos os significados da memória coletiva."

Na Região da Quarta Colônia de Imigração Italiana a arquitetura, um dos códigos culturais da etnia italiana, é fortemente percebida na paisagem local. Ainda existem, nos dias de hoje, muitos casarões históricos de construções típicas italianas; Estas casas eram feitas de pedras ou madeira, com telhados inclinados, grandes porões e cantinas que abrigavam os alimentos e o vinho, com muitas portas e janelas. A cozinha destas residências italianas era construída separadamente do resto da casa, com a funcionalidade de reunir tudo família nas refeições.

Ainda na arquitetura das casas, na sua maioria eram sobrados e havia sobre as portas e janelas desenhos de anjos e santos, reforçando a religiosidade italiana. Alguns destas antigas casas estão abandonadas outras, entretanto, pertencem habitadas pelos descendentes dos imigrantes italianos.

As ilustrações 2 e 3 mostram duas casas históricas de arquitetura italiana, a primeira não ocupada atualmente, componente do patrimônio histórico de Ivorá, enquanto, a segunda encontrase ainda ocupada por descendentes dos imigrantes, dos quais foram passadas de pais para filhos.

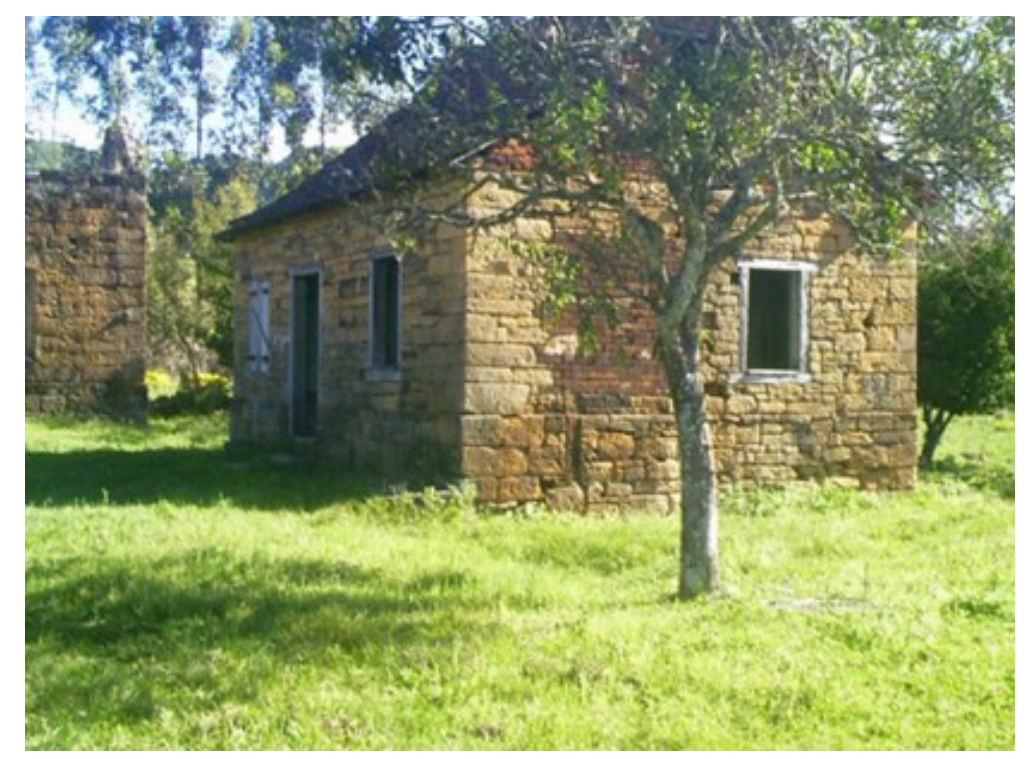

Ilustração 2- Casa colonial em Ivorá/RS

Fonte: Prefeitura Municipal de Ivorá

Geografia Ensino \& Pesquisa, v. 16, n.2 p. 31 - 46, maio/ago. 2012

Estas casas fazem parte hoje, da identidade da região. Os moradores destas residências fazem questão de conservar a memória dos seus antepassados, ao passo que consideram estas edificações um patrimônio histórico e cultural.

Manfio, V. 


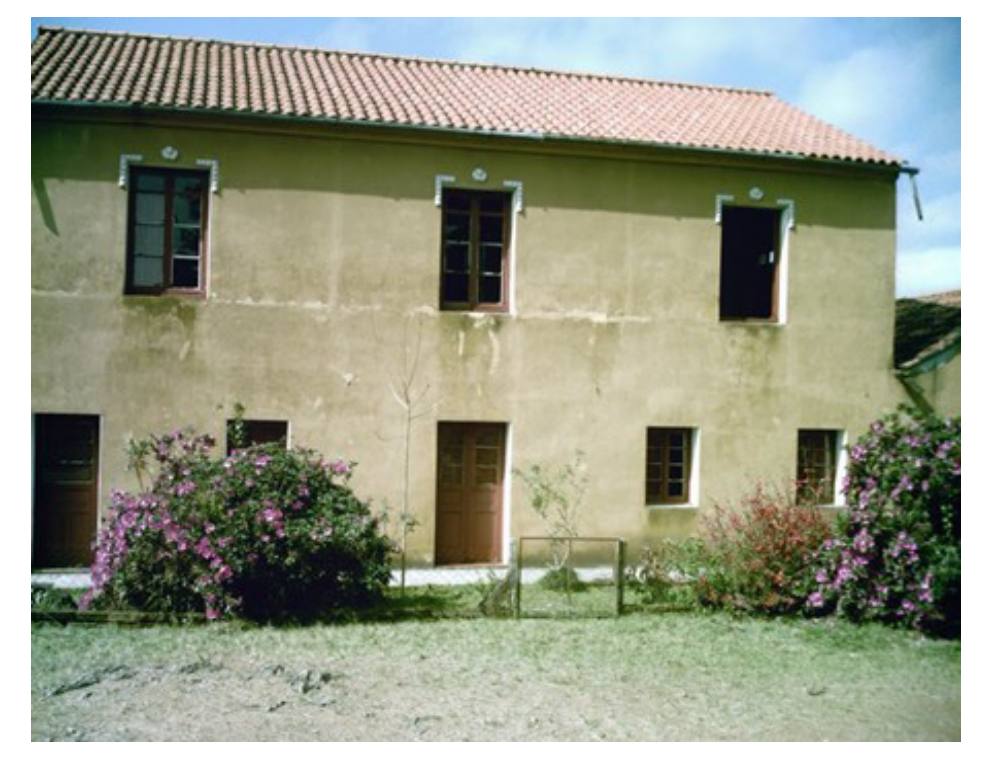

Ilustração 3- Casa colonial de Nova Palma Fonte: Foto do autor

Outro elemento da cultura italiana materializada sobre o espaço da Quarta Colônia de Imigração Italiana é a religião, pois os imigrantes italianos eram extremamente religiosos.

A presença do padre e da igreja surge antes mesmo da escola, a doutrina católica imposta aos imigrantes lá na Itália, permaneceu fortemente marcada nos então moradores da nova pátria, a Colônia Silveira Martins. Com isto, a religiosidade atravessou o oceano juntamente com a bagagem de conhecimentos dos italianos e o desejo de melhores oportunidades.

A religiosidade foi fundamental para a vivência nos primórdios no processo de imigração, contribuindo com o desenvolvimento dos municípios, como a prática social e no suporte em meio às dificuldades destes imigrantes.

Santi (1999, p.15) afirma que: "A reconstrução do ambiente de origem, através dos santos prediletos, dos capitéis, das igrejinhas, dos campanários e dos sinos, das cantorias, das festas tornaram-se os fundamentos desta nova terra." Reforça PICCIN (2009):

Neste contexto, a religião católica está presente na paisagem da Quarta Colônia de
Imigração Italiana como código cultural material e imaterial. (...) No entanto, destaca-se
que, na maioria das vezes, é a partir do aspecto imaterial que se consolida o material, ou
seja, a partir da fé, das promessas, entre outras manifestações religiosas é que tem se a
materialização da religião, expressa por meio dos símbolos religiosos, via construção das
igrejas, capitéis, grutas, entre outros. PICCIN, 2009 p. 88).

Observa-se que todas estes pequenos municípios que compõe a região têm na sua paisagem a presença de capitéis, igrejas e monumentos, sendo o lugar sagrado, o ponto mais importante das comunidades e lugares. Ilustração 4 e 5.

Esta religiosidade além de ser materializada na paisagem regional foi passada aos descen-

Geografia Ensino \& Pesquisa, v. 16, n.2 p. 31 - 46, maio/ago. 2012

A Quarta Colônia de imigração italiana: uma paisagem cultural na região central do Rio Grande do Sul. dentes italianos. Assim os moradores da região ainda nos dias atuais, guardam os ensinamentos religiosos e a religião como um alicerce da vida e do desenvolvimento.

Comenta PICCIN (2009, p. 101) que: "A conservação dos símbolos religiosos e a construção de outros, recentemente, revelam que a religião católica na Quarta Colônia de Imigração Italiana tem um papel significativo e é transmitida através das gerações, como um código cultural consolidado." 


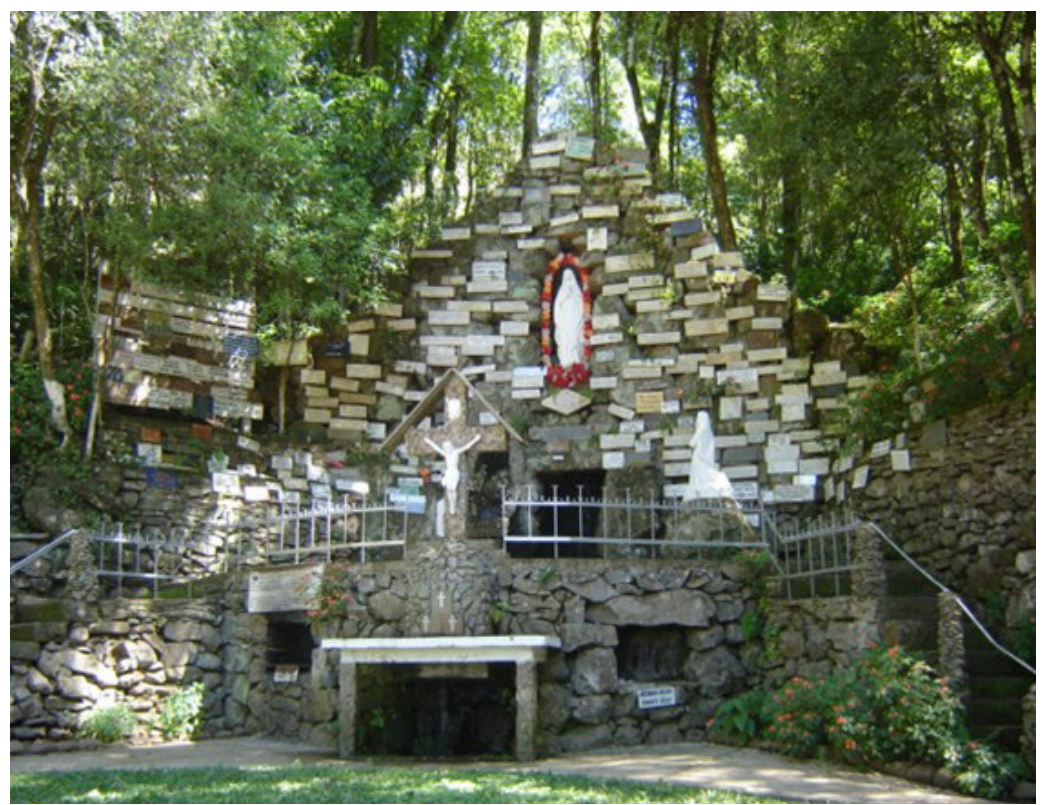

Ilustração 4- Gruta de N. Senhora de Lurdes- Nova Palma/RS.

Fonte: Prefeitura Municipal de Nova Palma

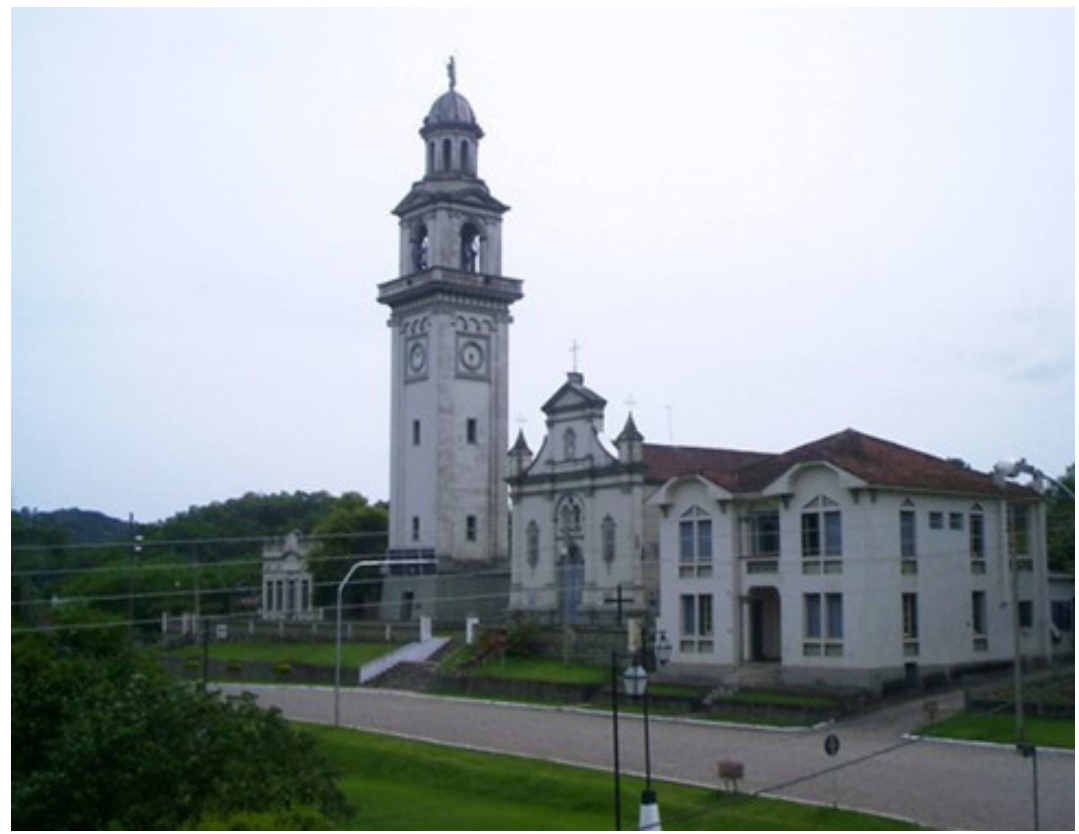

Ilustração 5- Igreja Matriz São José

Fonte: Prefeitura Municipal de Ivorá

Através da religião materializam-se sobre a região também, as festividades e encontros sociais reforçando o papel da religiosidade que não fica atrelado apenas na fé.

Assim, as festividades nesta região são na sua maioria em torno da religião. Como exemplos de festividades religiosas destacam-se: Festa de São João Batista, Festa de Nossa Senhora de Lurdes, Festa do Corpo de Deus, Festa de Nossa Senhora da Saúde entre outras.

As marcantes festas religiosas também são heranças dos imigrantes italianos que através do convívio e fé, tinham sua vivência em comunidade decorrente, sobretudo, pela religiosidade. Salienta Saquet $(2003$, p.93) que:

Geografia Ensino \& Pesquisa, v. 16, n.2 p. 31 - 46, maio/ago. 2012

Manfio, $\mathbf{V}$. 
"No inicio da colonização em Silveira Martins, as atividades sociais desses imigrantes eram limitadas as religiosas e, sobretudo nos dias festivos e domingos. (...) "após a missa, aproveitavam para fazer compras e jogar bocha e baralho (Tressette) sempre acompanhados do vinho." (SAQUET, 2003, p.93).

A participação na comunidade e as festas religiosas acompanharam os tempos, constituindo-se numa característica dos atuais moradores da Quarta Colônia de Imigração Italiana.

Além da arquitetura e da religiosidade, outros artefatos fazem parte da paisagem regional, entre eles monumentos em homenagem a colonização, parreirais de uva (que fazem parte da alimentação dos italianos que juntamente com os alimentos sempre tem associado o vinho, sendo os imigrantes italianos os responsáveis pelo cultivo da uva e fabricação do vinho), moinhos, fornos de barro, pequenas hortas nos quintais de residências, entre outros.

Muitos destes artefatos são ainda utilizados pelos moradores da região, como os formos de tijolos ainda utilizados no cozimento do pão, as pipas de vinho de madeira para o depósito do vinho em pequenas propriedades onde a bebida fica armazenada 0 ano todo. Tais como os hábitos italianos já que representa uma herança cultural.

Obviamente que a região não ficou parada no tempo, introduziu-se máquinas e ferramentas modernas, mas as tradicionais antigas fazem parte da paisagem regional, mesmo que não utilizados representam para estes descendentes de italianos um apego sentimental e a memória de vida, constituindo sua identidade cultural.

Na ilustração 6 apresenta-se uma imagem do Museu de Novo Treviso em Faxinal do Soturno com artigos da cultura italiana, elementos culturais que foram utilizados pelos imigrantes italianos e posteriormente por seus descendentes.

Os festivais que acontecem na região são todos marcados pela cultura italiana, onde sempre é visível, as crenças, a culinária (principalmente o queijo, a polenta e o vinho), a religião e a paisagem entre as festas mais típicas da Quarta Colônia estão: Festival do Vinho e Queijo, Amostra Gastronômica da Quarta Colônia, Jantar Italiano, Festival Internacional de Música de Vale Vêneto.

Contudo, a culinária italiana também é um aspecto essencial da cultura italiana na região, porém, neste trabalho não abordamos detalhadamente a linguagem e a culinária, pois não esta visível no espaço como os demais elementos, embora não menos importante que a arquitetura e religiosidade.

Entretanto, a paisagem é o visível e o imaginário, a materialização do espaço cultural desta região se dá também através de elementos como a gastronomia, os sentimentos dos moradores deste local, as lembranças e histórias contadas pelos mais velhos. 


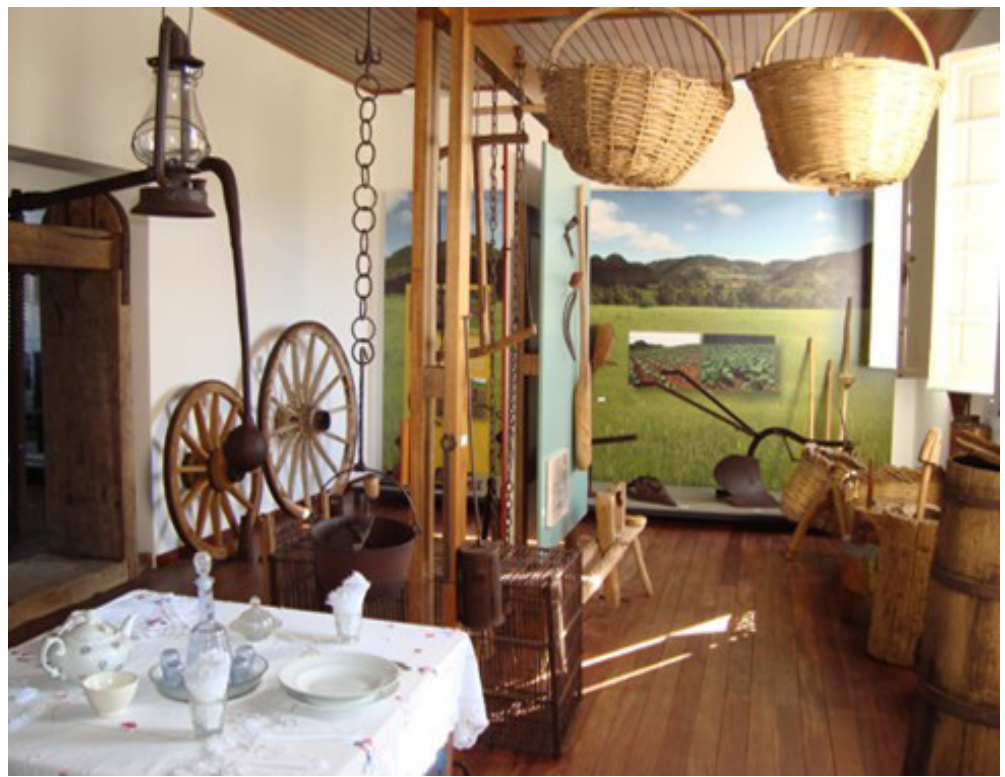

Ilustração 6- Elementos da cultura italiana

Fonte: Prefeitura de Faxinal do Soturno

A partir desta valorização e materialização do espaço pelos italianos e seus códigos culturais, a atividade turística neste ambiente desenvolveu despertando muitos visitantes e transformando as regiões de colonização italiana em verdadeiros espaços turísticos e extremamente conhecidos, como é o caso da Quarta Colônia de Imigração Italiana, nas quais apresentam junto as demais atividades econômicas, o turismo à cultura italiana, reestruturando o espaço e preservando os cenários colônias e as marcas da cultura.

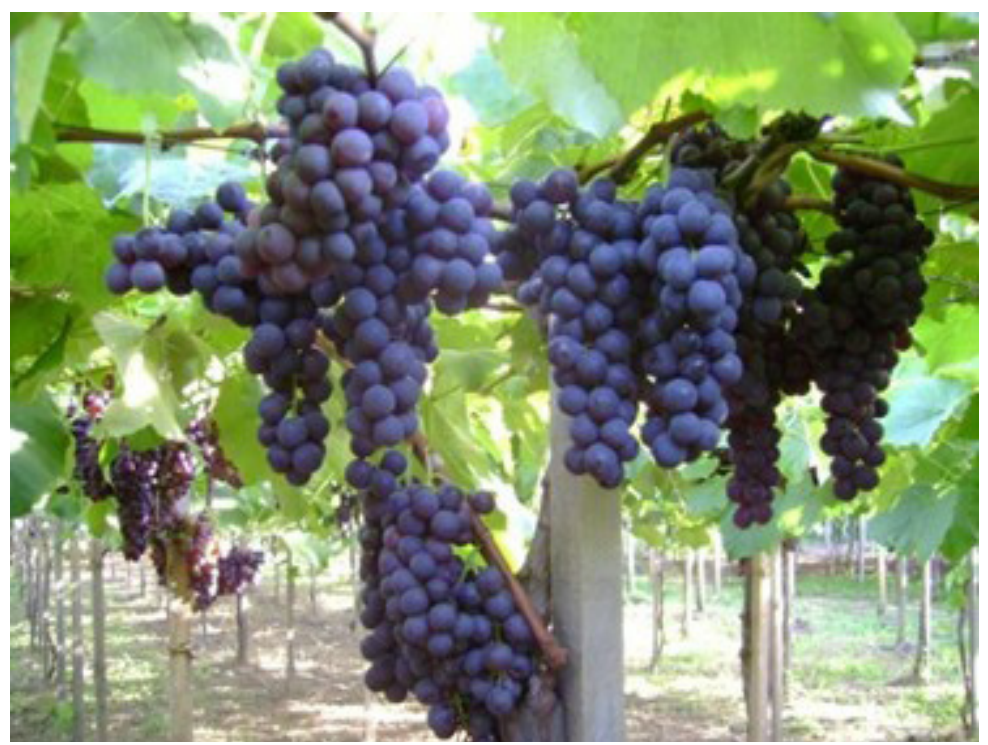

Ilustração 7: Parreirais de Uva/ Silveira Martins

Fonte: Prefeitura de Silveira Martins

O turismo, entretanto, é uma maneira de impedir que os efeitos da globalização sobre 0 espaço regional da Quarta Colônia de Imigração Italiana desconstruam a identidade do povo que ali habita. Constituindo ainda numa fonte de renda à região.

Aborda Torres (2009, p. 35) que: "A cultura é uma resposta ao fenômeno da globalização e graças a ela que a história e hábitos antigos ainda existem e cada vez são mais valorizados."

Geografia Ensino \& Pesquisa, v. 16, n.2 p. 31 - 46, maio/ago. 2012

Manfio, V.

Reforça Torres (2009, p.36) que: "Tudo isso significa desacelerar o ritmo imposto pela globalização e reencontrar-se com o passado." 
Com isto, mesmo que elementos do global incidam no regional da Quarta Colônia de Imigração Italiana, o desejo de manter presente suas raízes e o desenvolvimento do turismo têm permitido que a paisagem cultural ali formada permaneça inabalada.

Sem dúvidas, este sentimentalismo e memória cultural foi essencial para que através da preservação das raízes de identidade firma-se nesta paisagem uma nova atividade econômica, o turismo cultural.

Com isso, a paisagem formada na Quarta Colônia de Imigração Italiana é percebível através dos códigos culturais e históricos, mas também de sentimentos e lembranças, e são esta afetividade com o lugar e a cultura que dão significado a paisagem regional e o que atrai turistas a região na busca e conhecimento das raízes desta etnia e visualização do cenário cultural.

\section{Considerações}

A paisagem é um conjunto de elementos que exprimem significados, sentimentos e características sobre o lugar. Diante disso, a paisagem da Região da Quarta Colônia de Imigração Italiana é resultado da imigração italiana nesta região. Tal colonização italiana imprimiu identidade visivelmente associada ao espaço natural, cuja tradição no trato da terra deu lugar ao espaço próprio retratando seus valores, seus símbolos e sua cultura.

O trabalho, a cultura e a religião italiana deixaram suas expressões no território rio-grandense e na formação étnica brasileira e gaúcha. As belas paisagens culturais repletas de significados e sentimentalismo de uma população trabalhadora que reproduziu no natural o valor de suas origens e hábitos, desperta o interesse de muitos estudiosos e turistas.

Devido ao sentimentalismo dos moradores locais, a Quarta Colônia de Imigração Italiana guarda até os dias de hoje, particularidades típicas dos hábitos italianos, casarões antigos e de arquitetura italiana, religiosidade através da construção de inúmeros lugares sagrados, gastronomia entre outros códigos culturais.

Sem dúvidas, a região e os costumes dos imigrantes, juntamente com o trabalho, construíram no espaço geográfico rio-grandense um espaço cultural, através da reprodução da pátria de origem (Itália) e fortemente perceptível devido aos códigos culturais que se materializam sobre o lugar.

Contudo, a paisagem cultural é o que desperta as novas atividades econômicas, especialmente o turismo. Assim como os hábitos italianos tornam-se uma marca econômica e social, especifica da região e dos municípios colonizados pelos italianos. Esta marca, entretanto, caracteriza a região.

Em suma, esta paisagem cultural é reconhecida nacionalmente, e somente foi possível a preservação dos códigos culturais frente à globalização e os novos arranjos espaciais devido à ligação afetiva dos moradores da região em discussão. Com isto, a revitalização deste cenário colonial trás o desenvolvimento local, sendo importante o planejamento e as políticas públicas regionais $\mathrm{e}$ municipais na ordem de manter destacado na paisagem o velho e o novo. Caso contrário a região perderá sua identidade cultural, ou melhor, sua própria identidade.

Obstante é importante o crescimento de modernos espaços e recursos, mas a harmonia

Geografia Ensino \& Pesquisa, v. 16, n.2 p. 31 - 46, maio/ago. 2012

A Quarta Colônia de imigração italiana: uma paisagem cultural na região central do Rio Grande do Sul.

\section{Referências Bibliográficas}

ALMEIDA, A. P.; SARTORI, M. da G. B. "A percepção da paisagem urbana de Santa Maria-RS e os sentimentos de topofilia e topofobia de seus moradores." Ciência e Natura, UFSM, 30 (2): $107-126,2008$. 
BOLÓS I CAPDEVILA, M. de. Manual de ciencia del paisaje: Teória, métodos y aplicaciones. Barcelona: Masson, 1992.

BRUM NETO, H. Regiões Culturais: A construção de identidades culturais no Rio grande do Sul e sua manifestação na paisagem gaúcha. 2007. 328f. Dissertação (Mestrado em Geografia) - Universidade Federal de Santa Maria, Santa Maria, 2007.

BRUNET. Le déchiffrement du monde: théorie et pratique de la géographie. Paris: Belin, 2001.

CHIAMULERA, M. Identidade em performance: Um estudo etnográfico sobre as festas de capela no "berço" da Quarta Colônia de Imigração Italiana/RS. 2010. 223f. Dissertação (Mestrado em Ciências Sociais) - Universidade Federal de Santa Maria, Santa Maria, 2010.

CLAVAL, P. A Geografia Cultural: o estado da arte. In: CORRÊA, R.L. et al. (org.). Manifestações da Cultura no Espaço. Rio de Janeiro: EdUERJ, 1999.

. As abordagens da Geografia Cultural. In: INÁ Elias de Castro et al (Org). Explorações Geográficas. Rio de Janeiro: Bertrand Brasil, 1997.

CORRÊA, R. L. A dimensão cultural do espaço: Alguns temas. In: Corrêa, R. L. Trajetórias Geográficas. 2 ed. Rio de Janeiro: Bertrand Brasil, 2001.

CORRÊA, R. L. \& ROZENDAHL, Z. Apresentando leituras sobre paisagem, tempo e cultura. In: CORREAA, R. L. \& ROZENDAHL, Z. (org.). Paisagem, Tempo e Cultura. Rio de Janeiro: EDUERJ, 1998.

COSGROVE, D. E. A Geografia está em toda parte: cultura e simbolismo nas paisagens humanas. In: CORREAA, Roberto L..; ROSENDAHL, Zeny (orgs). Paisagem, Tempo e Cultura. Rio de Janeiro: EDUERJ, 1998. p. 92-123.

DE BONI, L. A.; COSTA, R. Os imigrantes italianos. Porto Alegre; Caxias do Sul: EST; UCS, 1979.

FROEHLICH, J. M. et. al. Narrando Territorialidade: Identidade Territorial da Quarta Colônia - RS. In: Congresso da Sociedade Brasileira de Economia, Administração e Sociologia Rural, 47, Porto Alegre, 2009. Disponível em: www.sober.org.br/palestra/13/818.pdf. Acesso em: Nov. 2010.

GIRON, L. S.; HERÉDIA, V. Cultura e religião. In: GIRON, L. S.; HERÉDIA, V. História da Imigração Italiana no Rio Grande do Sul. Porto Alegre: Est, 2007.

MAGALHÃES, S. M. A Chancela da Paisagem Cultural Brasileira e os Jardins Histórico." In: XXVI Simpósio Nacional de História - ANPUH, São Paulo, 2011. Anais... Disponível em: http:/l www.snh2011.anpuh.org/resources/anais/14/1308098302_ARQUIVO_CristianeMariaMagalhaesachancelaeosjardinshistoricos.pdf. Acesso em: 10 jan. 2012.

MANFIO, V.; BENADUCE, G. M. C. A Quarta Colônia de Imigração Italiana: A Valorização Cultural da Região. In: Simpósio de Ensino, Pesquisa e Extensão, XIV. Santa Maria, 2010. Anais... Disponível em: http://www.unifra.br/eventos/sepe2010/2010/Trabalhos/humanas/Completo/4596.pdf . Acesso em 12 fev. 2011.

MANFROI, O. A Colonização italiana no Rio Grande do Sul: implicações econômicas, político e culturais. 2 ed. Porto Alegre: EST, 2001.

Geografia Ensino \& Pesquisa, v. 16, n.2 p. 31 - 46, maio/ago. 2012

MARIN, J. (org.). Quarta Colônia: Novos olhares. Porto alegre: EST, 1999. 
Combatendo nos exércitos de Deus: as associações devolucionais e o projeto de romanização da igreja católica. In: MARIN, J. (org.). Quarta Colônia: Novos Olhares. Porto Alegre: EST, 1999. p.74-94.

MASSEY, D. B. Pelo espaço: uma nova política da espacialidade. Trad. HILDA PARETO MACIEL; ROGÉRIO HAESBAERT. Rio de Janeiro: Bertrand Brasil, 2008. 312 p.

PICCIN, E. O Código Cultural Religião Como Uma das Manifestações da Identidade Cultural da Quarta Colônia de Imigração Italiana/RS. 2009. 148f. Dissertação (Mestrado em Geografia) - Universidade Federal de Santa Maria, Santa Maria, 2009.

PORTAL DA QUARTA COLÔNIA. Quarta Colônia- RS. Disponível em: http://quartacolonia. prumosweb.com.br/quartacolonia_donafrancisca.jsp. Acesso em: 27 nov. 2010.

PREFEITURA DE FAXINAL DO SOTURNO. Histórico do município. Disponível em: <http:// www.faxinal.com/o-municipio/historico. Acesso em: 20 jul. 2010.

PREFEITURA MUNICIPAL DE IVORÁ. Histórico do município. Disponível em: http://www.ivora. rs.gov.br/index.php?site=turismo.php>. Acesso em: 15 ago. 2010.

PREFEITURA MUNICIPAL DE NOVA PALMA. Dados do município. Disponível em: << http:// www.novapalma.rs.gov.br/>. Acesso em: 15 de ago. 2010.

PREFEITURA MUNICIPAL DE SILVEIRA MARTINS. Dados do Município. Disponível em: $<w w w . s i l v e i r a m a r t i n s . r s . g o v . b r$. Acesso em: 14 ago. 2010.

PREFEITURA MUNICIPAL DE SÃO JOÃO DO POLÊSINE. Dados do Município. Disponível em: < http://www.polesine.com.br/>. Acesso em: 25 jul. 2010.

SALGUEIRO, T. B. Paisagem e Geografia. Finisterra. v. 72, p. 37-53, 2001.

SANTI, S. Sonhos diferenciados ou desfeitos: Silveira Martins, a Quarta Colônia, no cenário da Imigração Italiana no Rio Grande do Sul. In: MARIN, J. (org.). Quarta Colônia: Novos Olhares. Porto Alegre: EST, 1999. p.11-24.

SANTOS, Milton. Técnica Espaço Tempo: Globalização e Meio Técnico Científico Informacional. São Paulo. Ed. Hucitec. 1997.

Edusp, 2002.

A natureza do espaço: técnica e tempo - razão e emoção. São Paulo:

SAQUET, M. A. Alguns aspectos da formação econômica da ex- colônia Silveira Martins (18781925)." In: MARIN, J. (org.). Quarta Colônia: Novos Olhares. Porto Alegre: EST, 1999.

Colonização italiana e agricultura familiar. 1. ed. Porto Alegre: EST

Geografia Ensino \& Pesquisa, v. 16, n.2 p. 31 - 46, maio/ago. 2012

A Quarta Colônia de imigração italiana: uma paisagem cultural na região central do Rio Grande do Sul.
Edições, 2002. 112 p.

Os tempos e os territórios da colonização italiana: o desenvolvimento econômico da Colônia de Silveira Martins (RS). Porto Alegre, EST, 2003.

SILVA, J. M. Cultura e Territorialidades Urbanas - Uma Abordagem da Pequena Cidade. Revista História Regional. v. 5, n. 2, p. 9- 37 , 2000. Disponível em: www.revistas2.uepg.br/index.php/ rhr/article/view/2109/1590. Acesso em: set. 2010. 
SUERTEGARAY, D. M. A. . Espaço Geográfico Uno e Múltiplo. Scripta Nova (Barcelona), Barcelona, v. 93, 2001.

SPONCHIADO, B. A. Imigração \& Quarta Colônia: Nova Palma e Pe.Luizinho. Nova Palma: Paróquia Santíssima Trindade; Santa Maria: Ed. da UFSM, 1996.

TORRES, T. G. A construção do espaço pelo turismo: Rota Turística gastronômica de Santa Maria e Silveira Martins, RS. 2009, 107f. Dissertação ( Mestrado em Geografia) Universidade Federal de Santa Maria, Santa Maria, 2009.

TUAN, Yi-Fu. Espaço e lugar: a perspectiva da experiência. Tradução de Lívia de Oliveira. São Paulo: DIFEL, 1983.

VENDRUSCOLO, R. Somos da Quarta Colônia: Os sentimentos de uma identidade territorial em construção. 2009. 210f. Dissertação (Mestrado em Extensão Rural)- Universidade Federal de Santa Maria, Santa Maria, 2009.

VENDRUSCOLO, R. et al. Imprimindo Sabores - Gastronomia e Identidade Territorial na Quarta Colônia -RS. In: Congresso da Sociedade Brasileira de Economia, Administração e Sociologia Rural, XLVI, Rio Claro, 2008.Disponível em: http://www.sober.org.br/palestra/9/521. pdf. Acesso em: 23 mar. 2011.

\section{Correspondência:}

Vanessa Manfio - Universidade Federal de Santa Maria, Centro de Ciências Naturais e Exatas. Av. Roraima 1000, Campus da UFSM, prédio 17, Departamento de Geociências. Camobi. 97105900 - Santa Maria, RS

E-mail: nessamanfio@gmail.com

Recebido em 04 de novembro de 2011.

Revisado pelo autor em 03 de janeiro de 2012.

Aceito para publicação em 24 de fevereiro de 2012. 